\title{
Propionate induces mRNA expression of gluconeogenic genes in bovine calf hepatocytes
}

Qian Zhang, Stephanie L. Koser, and Shawn S. Donkin ${ }^{1}$
Department of Animal Sciences, Purdue University, West Lafayette 47907

\begin{abstract}
Hepatocytes monolayers from neonatal calves were used to determine the responses of the cytosolic phosphoenolpyruvate carboxykinase (PCK1) mRNA expression to propionate and direct hormonal cues including cyclic AMP (cAMP), dexamethasone, and insulin. The responses of other key gluconeogenic genes, including mitochondrial phosphoenolpyruvate carboxykinase $(P C K 2)$, pyruvate carboxylase $(P C)$, and glucose6-phosphotase $(G 6 P C)$, were also measured. Expression of $P C K 1$ was linearly induced with increasing propionate concentrations in media and $2.5 \mathrm{~m} M$ propionate increased PCK1 mRNA at 3 and $6 \mathrm{~h}$ of incubation; however, the induction disappeared at 12 and $24 \mathrm{~h}$. The induction of PCK1 mRNA by propionate was mimicked by $1 \mathrm{~m} M$ cAMP, or in combination with $5 \mu M$ dexamethasone, but not by dexamethasone alone. The induction of PCK1 mRNA by propionate or cAMP was eliminated by addition of $100 \mathrm{n} M$ insulin. Additionally, expression of $P C K 2$ and $P C$ mRNA was also induced by propionate in a concentration-dependent manner. Consistent with PCK1, propionate-stimulated PCK2 and $P C$ mRNA expression was inhibited by insulin. Expression of $G 6 P C$ mRNA was neither affected by propionate nor cAMP, dexamethasone, insulin, or their combinations. These findings demonstrate that propionate can directly regulate its own metabolism in bovine calf hepatocytes through upregulation of $P C K 1, P C K 2$, and $P C$ mRNA expression.
\end{abstract}

Key words: PCK1, hormonal regulation, gluconeogenesis

\section{INTRODUCTION}

The importance of gluconeogenesis in ruminants is highlighted by the extensive fermentation of simple sugars and starch in the rumen, despite extensive meta-

Received August 25, 2015.

Accepted December 4, 2015.

${ }^{1}$ Corresponding author: sdonkin@purdue.edu bolic needs for glucose by tissues and as a precursor for milk lactose synthesis (Aschenbach et al., 2010). Hypoglycemia, ketosis, and related metabolic disorders are often observed when gluconeogenic capacity in the liver fails to adapt to the increased tissue demands for glucose in dairy cattle (Aschenbach et al., 2010). The prevalence of this insufficiency is highlighted by reports that the incidence of ketosis in commercial dairy herds may be as high as 17\% (Dohoo and Martin, 1984). Because propionate contributes approximately $50 \%$ of the carbon for gluconeogenesis (Huntington, 1990), strategies to increase propionate supply, including monensin feeding, have successfully reduced the incidence of ketosis in transition dairy cows (Duffield et al., 1998). In addition to the documented effect of monensin on feed efficiency and increased ruminal propionate production (Sauer et al., 1989), a portion of the effect of monensin in transition cows may be linked to increased capacity for gluconeogenesis through enhanced expression of cytosolic phosphoenolpyruvate carboxykinase (PCK1), a key gene for glucose synthesis (Karcher et al., 2007).

Control of PCK1 enzyme activity has been studied extensively in nonruminants and is primarily exerted through transcription of the gene via activation of basal, tissue-specific, and hormone-dependent promoter elements within the 5 'flanking region of the PCK1 gene (Hanson and Reshef, 1997). Expression of PCK1 mRNA in nonruminants is activated by glucagon and glucocorticoids and insulin counteracts these effects (O'Brien and Granner, 1990). A lack of response for PCK1 to feed restriction in dairy cows (Velez and Donkin, 2005) and sheep (Filsell et al., 1969; Taylor et al., 1971; Smith et al., 1982) is in direct contrast with data from nonruminants demonstrating that feed restriction induces the PCK1 gene (Hanson and Reshef, 1997). Although in vivo administration of glucagon in dairy cattle suggests $P C K 1$ induction in dairy cattle (Bobe et al., 2009), these data are equivocal perhaps due to counter-regulatory release of insulin and other hormones (Bobe et al., 2009) in the experimental models used.

Regulation of PCK1 in response to glucagon and other hormones has been extensively studied in rat hepatocytes and hepatoma cells. The mRNA for PCK1 
is maximally induced by cyclic AMP (cAMP) in presence of glucocorticoids within $3 \mathrm{~h}$ (Christ et al., 1988). Likewise, short-chain fatty acids, including propionate, induce PCK1 mRNA in rat hepatocytes (Massillon et al., 2003), indicating the potential for propionate to control its own metabolism. Effects of glucagon on propionate and lactate metabolism in hepatocytes from neonatal calves indicate increased gluconeogenesis from propionate and lactate, but not glycerol (Donkin and Armentano, 1994), suggesting a regulation point of $P C K 1$ by glucagon. However, the direct effects of propionate and hormones on PCK1 mRNA in bovine hepatocytes have not been determined. We hypothesized that propionate and cAMP act to induce $P C K 1 \mathrm{mRNA}$ expression and insulin opposes these effects on PCK1 mRNA in liver hepatocytes.

The primary objective of the current research was to determine the direct effects of propionate, cAMP, dexamethasone, and insulin on mRNA expression of $P C K 1$ in the neonatal calf hepatocytes. The secondary objective was to evaluate the relative effects of propionate and these hormonal cues on mRNA expression of other key gluconeogenic genes, including mitochondrial phosphoenolpyruvate carboxykinase ( $P C K 2)$, pyruvate carboxylase $(P C)$, and glucose-6-phosphatase $(G 6 P C)$.

\section{MATERIALS AND METHODS}

\section{Care and Use of Hepatocyte Donor Animals}

All experimental procedures involving animals were approved by the Purdue University Animal Care and Use Committee. Three intact male dairy calves were used as hepatocyte donor animals. All calves received $3.8 \mathrm{~L}$ of superior colostrum for the first feeding postpartum and $1.9 \mathrm{~L}$ of superior colostrum during the first $48 \mathrm{~h}$ of life, for a total of $5.7 \mathrm{~L}$. Calves subsequently received milk at $10 \%$ of $\mathrm{BW}$ in 2 equal feedings per day. Calves were housed in a drying pen for the first $24 \mathrm{~h}$, then moved to individual calf hutches. At less than $7 \mathrm{~d}$ of age, the calves ( $47 \pm 3 \mathrm{~kg}$ of BW) were given heparin (1,000 USP, Sagent Pharmaceuticals, Schaumburg, IL) intravenously and anesthetized with $1 \%$ propofol (6 $\mathrm{mg} / \mathrm{kg}$ of calf BW, Hospira Inc., Lake Forest, IL) via intravenous injection. The caudate process was excised and the animals were euthanized immediately by intravenous injection of saturated potassium chloride (150 $\mathrm{mg} / \mathrm{kg}$ of calf BW, Sigma-Aldrich, St. Louis, MO).

\section{Hepatocyte Monolayer Preparation and Culture}

Liver cells were dispersed via collagenase perfusion as described previously (Donkin and Armentano, 1993). The isolated hepatocytes were plated on 35-mm Falcon
Primaria Easy Grip tissue culture dish (Becton Dickinson, Lincoln Park, NJ) at an approximate density of 5.3 $\times 10^{4}$ cells $/ \mathrm{cm}^{2}$ in Dulbecco's Modified Eagles Medium (DMEM) containing 20\% fetal bovine serum and 1\% antibiotic, antimycotic solution (Sigma-Aldrich). After $4 \mathrm{~h}$, the plating medium and unattached cells were removed by aspiration and media was replaced by DMEM containing $10 \%$ fetal bovine serum and $1 \%$ antibiotic, antimycotic solution.

Twenty hours after seeding, the media was removed by aspiration and replaced with DMEM supplemented with 1\% BSA (Merck Millipore, Billerica, MA) and $1 \%$ antibiotic, antimycotic solution, and the respective treatment additions. Time-dependent effect of propionate exposure was determined in the presence of either 0 or $2.5 \mathrm{mM}$ propionate for $3,6,12$, and $24 \mathrm{~h}$. Concentration dependence to propionate was determined in the presence of $0,0.625,1.25,2.5$, and $5.0 \mathrm{~m} M$ propionate for $6 \mathrm{~h}$. The effects of hormone additions and their relationship with propionate were tested using $1 \mathrm{mM}$ 8-Br-cAMP, $5 \mu M$ dexamethasone, $100 \mathrm{n} M$ insulin, 2.5 $\mathrm{m} M$ propionate, or their designated combinations over a period of $6 \mathrm{~h}$.

\section{RNA Extraction and PCR}

Total RNA was isolated using RNeasy Mini Kit (Qiagen, Inc., Thousand Oaks, CA) and quantified by absorbance at $260 \mathrm{~nm}$ using a ND-1000 (NanoDrop Technologies, Inc., Wilmington, DE). A total of $2 \mu \mathrm{g}$ of purified sample was reverse transcribed to cDNA using an Omniscript reverse transcriptase kit (Qiagen, Inc.), random decamers (Ambion, Foster City, CA), and oligo-dT (Qiagen, Inc.). Abundance of cDNA product for each RNA sample was quantified using real-time PCR, Brilliant III Ultra-Fast SYBR Green QPCR Master Mix (Agilent Technologies, Inc., Santa Clara, CA) with primers described below. A cDNA pool was generated from an equivalent quantity of cDNA from each sample. A 1:4 dilution series of the cDNA pool was used to generate the standard curve. No-template control (using water as template) and no-reverse transcription control (using RNA pool as template) were included in the real-time PCR analysis. The forward and reverse primers, respectively, for PCK1, PCK2, $P C, G 6 P C$, GAPDH, and $18 S$ were: bovine PCK1 (GenBank accession: NM_174737.2), AGGGAAATAGCAGGCTCCAGGAAA, CACACGCATGTGCACACACACATA; bovine PCK2 (GenBank accession: NM_001205594.1), TGACTGGGCAAGGGGAGCCG, GGGGCCACCCCAAAGAAGCC; bovine $P C$ (GenBank accession: NM_177946.4), CCACGAGT TCTCCAACACCT, TTCTCCTCCAGCTCCTCGTA; bovine G6PC (GenBank accession: NM_001076124.2), 
TGATGGACCAAGAAAGATCCAGGC, TATGGATTGACCTCACTGGCCCTCTT; bovine GAPDH (GenBank accession: NM_001034034.2), CATGTT TGTGATGGGCGTGAACCA, TGATGGCGTGGACAGTGGTCATAA; and bovine 18S (GenBank accession: NR_036642.1), ACCCATTCGAACGTCTGCCCTATT, TCCTTGGATGTGGTAGCCGTTTCT. Reactions were 1 cycle at $95^{\circ} \mathrm{C}$ for $3 \mathrm{~min}$; 40 cycles at $95^{\circ} \mathrm{C}$ for $10 \mathrm{~s}, 60^{\circ} \mathrm{C}$ for $20 \mathrm{~s}$; and 1 cycle at $95^{\circ} \mathrm{C}$ for $1 \mathrm{~min}, 55^{\circ} \mathrm{C}$ for $30 \mathrm{~s}$, and $95^{\circ} \mathrm{C}$ for $30 \mathrm{~s}$. Samples were analyzed in triplicate and PCR reaction efficiencies were between 90 and $110 \%$. The cycle threshold values for treatments were evaluated independently for $G A P D H$ and $18 S$ as potential housekeeping genes. There was no effect of treatment on either transcript. The copy number for $18 S$ showed less variation among samples compared with GAPDH, and mean values for transcripts evaluated were normalized to mRNA abundance of $18 S$ within each sample. Data are expressed as arbitrary units of mRNA adjusted for $18 S$ abundance.

\section{Statistical Analysis}

All experiments were conducted in 3 separate cell preparations from 3 calves using 3 replicates per treatment. Data were analyzed for normality using the Univariate procedure of SAS 9.2 (SAS Inst. Inc., Cary, NC), and any heteroscedastic data were adjusted to achieve normality using a natural logarithm transformation. Analyses of variance were performed using the Proc Mixed procedure of SAS. For analyzing data associated with time, the model accounted for the random effect of cell preparation, the fixed effect of time, treatment, and time by treatment interaction. For data that had a significant time by treatment interaction, comparisons between treatments at the same time point were made using pdiff option. For data not associated with an effect of time, the model accounted for the random effect of cell preparation and fixed effects of treatment. Dunnett's test was used for comparisons between each hormonal treatment and the no-addition control. Data are reported as least squares means and standard errors. Means were considered different when $P \leq 0.05$ and a tendency for difference was declared when 0.05 $<P \leq 0.10$.

\section{RESULTS}

Abundance of $P C K 1, P C K 2$, and $P C$ mRNA was induced $(P \leq 0.05)$ by $2.5 \mathrm{~m} M$ propionate, but no effect of propionate on $G 6 P C$ was noted (Figure 1). A treatment by time interaction $(P \leq 0.05)$ was detected for $P C K 1 \mathrm{mRNA}$ in response to incubation with $2.5 \mathrm{mM}$ propionate. Propionate induced $P C K 1 \mathrm{mRNA}$ to $188 \%$ of control at $3 \mathrm{~h}$ (2.65 vs. 1.41) and $163 \%$ of control at $6 \mathrm{~h}(2.43$ vs. 1.49$)$, but the response to propionate dissipated by $12 \mathrm{~h}$ so that a lack of effect $(P>0.10)$ was observed for both 12 and $24 \mathrm{~h}$. Expression of PCK2 mRNA was induced $(P \leq 0.05)$ to approximately $350 \%$ of control at 3 (0.74 vs. 0.21$), 6$ (0.67 vs. 0.19), 12 (0.54 vs. 0.15$)$, and $24 \mathrm{~h}$ (0.35 vs. 0.10). Propionate induced $(P \leq 0.05) P C$ mRNA to approximately 130 to $140 \%$ of control at 3 (0.96 vs. 0.69$), 6$ (1.00 vs. 0.72$), 12$ (1.07 vs. 0.79$)$, and $24 \mathrm{~h}$ (1.21 vs. 0.94$)$. The expression of $G 6 P C$ mRNA was not affected $(P>0.10)$ by propionate at any time point tested.

The effect of increasing propionate concentration on expression of PCK1, PCK2, PC, and G6PC mRNA in bovine hepatocytes was investigated by exposing to initial concentrations of propionate at $0,0.625,1.25$, and $2.5 \mathrm{mM}$ for $6 \mathrm{~h}$ (Figure 2). Expression of PCK1, $P C K 2$, and $P C$ showed a linear trend $(P \leq 0.05)$ with increasing propionate concentrations. In contrast, the expression of $G 6 P C$ mRNA was not affected $(P>0.10)$ by any of the concentrations tested.

In addition to the significant induction $(P \leq 0.05)$ of $P C K 1 \mathrm{mRNA}$ expression by propionate, expression of $P C K 1 \mathrm{mRNA}$ also tended to increase $(0.05<P \leq$ $0.10)$ in response to incubation with $1.0 \mathrm{~m} M \mathrm{cAMP}$ and the combination of $1.0 \mathrm{mM}$ cAMP and $5.0 \mu M$ dexamethasone, but was not altered $(P>0.10)$ by $5.0 \mu M$ dexamethasone alone (Figure 3). In presence of $100 \mathrm{n} M$ insulin, the expression of $P C K 1 \mathrm{mRNA}$ by propionate, cAMP, or the combination of cAMP and dexamethasone was repressed to the basal level. Similarly, propionate increased $(P \leq 0.05)$ mRNA expression of $P C K 2$ and $P C$, which was inhibited back to the basal level by insulin, whereas cAMP and dexamethasone had no effects on these 2 genes (Figure 3). The G6PC mRNA was not affected $(P>0.10)$ by any of the hormonal combinations tested (Figure 3 ).

\section{DISCUSSION}

Cytosolic phosphoenolpyruvate carboxykinase catalyzes formation of phosphoenolpyruvate from oxaloacetate (OAA), a critical reaction for gluconeogenesis in liver and kidney. The induction of PCK1 mRNA by cAMP in cultured calf hepatocytes is consistent with the effect observed for this second messenger of glucagon action in rat hepatocytes (Salavert and Iynedjian, 1982; Christ et al., 1988) and rat hepatoma cells (Sasaki et al., 1984; Granner et al., 1986). Likewise, the lack of induction of PCK1 mRNA by dexamethasone alone is in agreement with the observations in rat hepatocytes showing dexamethasone as a permissive factor for induction of PCK1 mRNA by glucagon rather than a stimulatory factor when present alone (Salavert and 
Iynedjian, 1982; Christ et al., 1988). The dominant inhibitory effect of insulin on cAMP-induced PCK1 mRNA is again consistent with studies in using rat liver cells (Granner et al., 1983). The data support that the overall responses to these hormone signals on PCK1 mRNA are similar for rat and bovine.
An increase in PCK1 mRNA has been associated with increased feed intake during early lactation in dairy cows (Greenfield et al., 2000), a circumstance also linked to increased ruminal propionate production. We determined the direct role of propionate on regulation of PCK1 mRNA expression in bovine by using
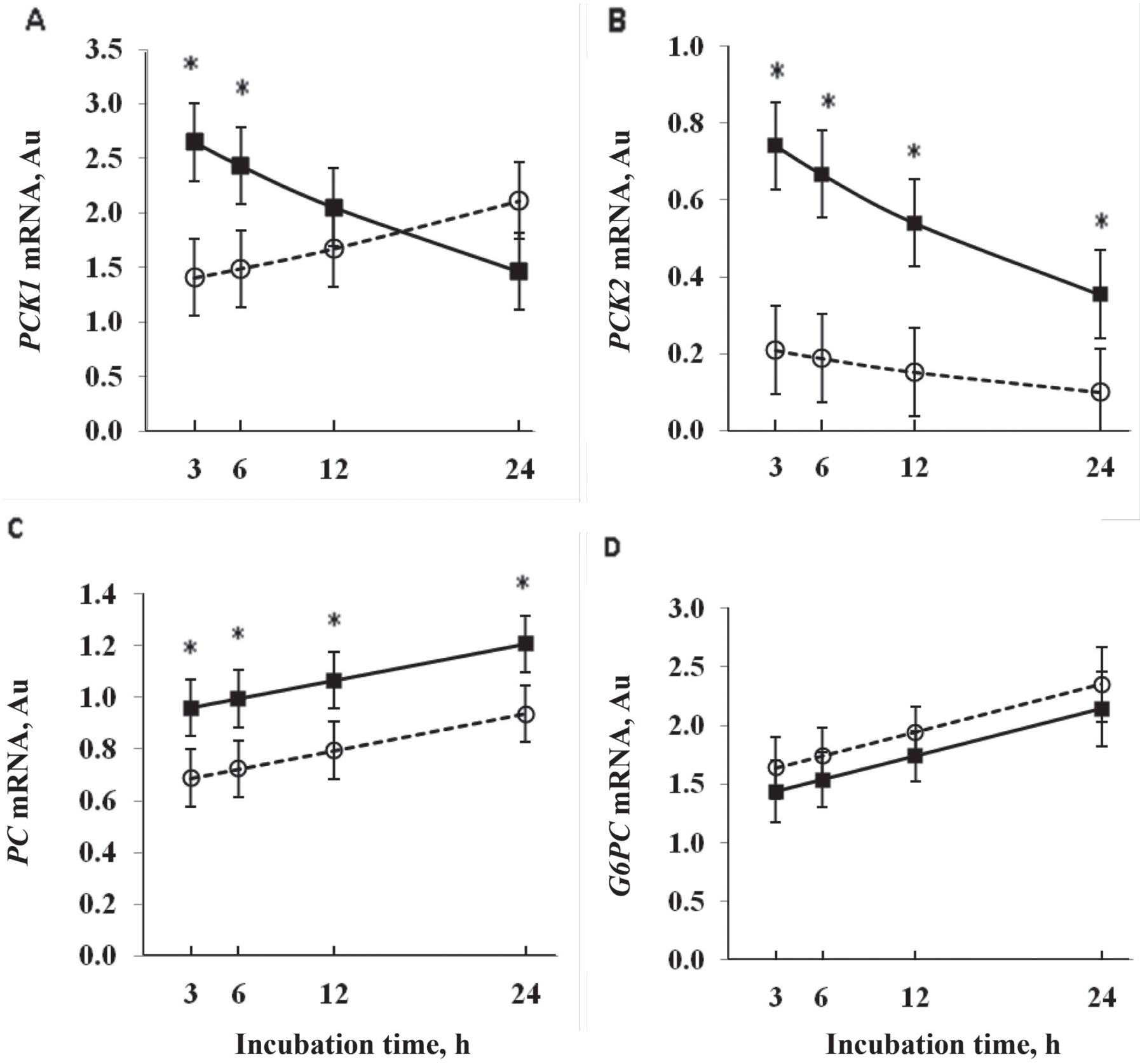

Figure 1. (A) Effect of propionate on expression of cytosolic phosphoenolpyruvate carboxykinase (PCK1) mRNA, (B) mitochondrial phosphoenolpyruvate carboxykinase $(P C K 2)$ mRNA, $(\mathrm{C})$ pyruvate carboxylase $(P C)$ mRNA, and (D) glucose-6-phosphotase $(G 6 P C)$ mRNA in bovine calf hepatocytes. After $24 \mathrm{~h}$, hepatocytes were exposed to either 0 (dotted line, open circle) or $2.5 \mathrm{~m} M$ propionate (solid line, solid square) for the interval indicated and harvested for mRNA analysis. Data are expressed as arbitrary units of mRNA adjusted for 18S abundance. Values are $\mathrm{LSM} \pm \mathrm{SE}(\mathrm{n}=3$ cell preparations). The symbol $(*)$ indicates means within the same time point differ $(P \leq 0.05)$. 
a primary hepatocyte culture system and, therefore, avoided any compensatory responses to nutrient supply or hormonal status often observed in vivo in response to shift in nutrient status. The induction of PCK1 mRNA by propionate observed here expands the previous observation that propionate induces PCK1 mRNA (Massillon et al., 2003) to include both rat and bovine. The opposing effect of insulin to repress propionate induction of $P C K 1$ mRNA confirms previous speculation that insulin blunts the maximal effect of propionate on PCK1 mRNA in vivo during the postruminal infusion of propionate in lactating dairy cows (Zhang et al., 2015). This is the first study, to our knowledge, that has investigated the relationship of propionate

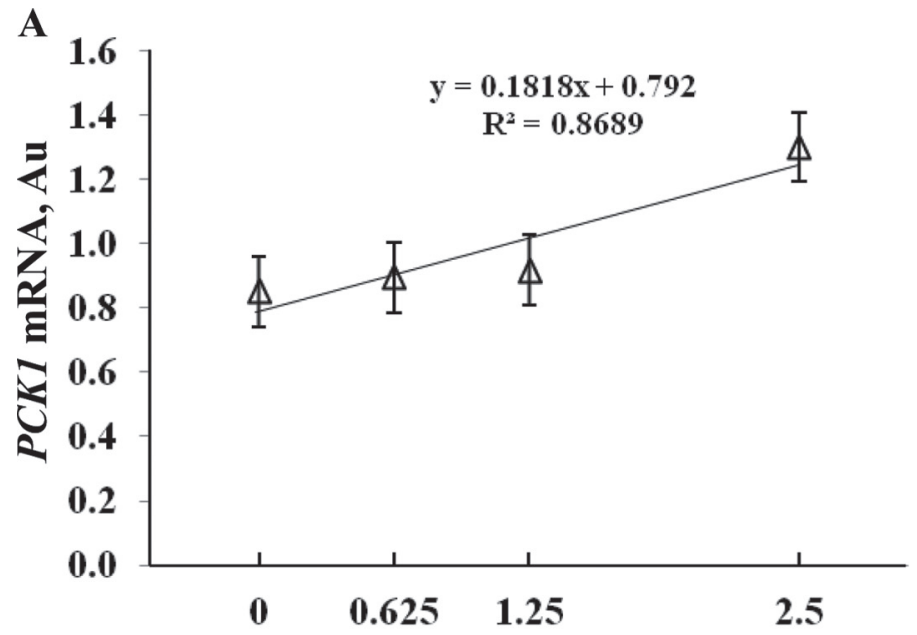

C

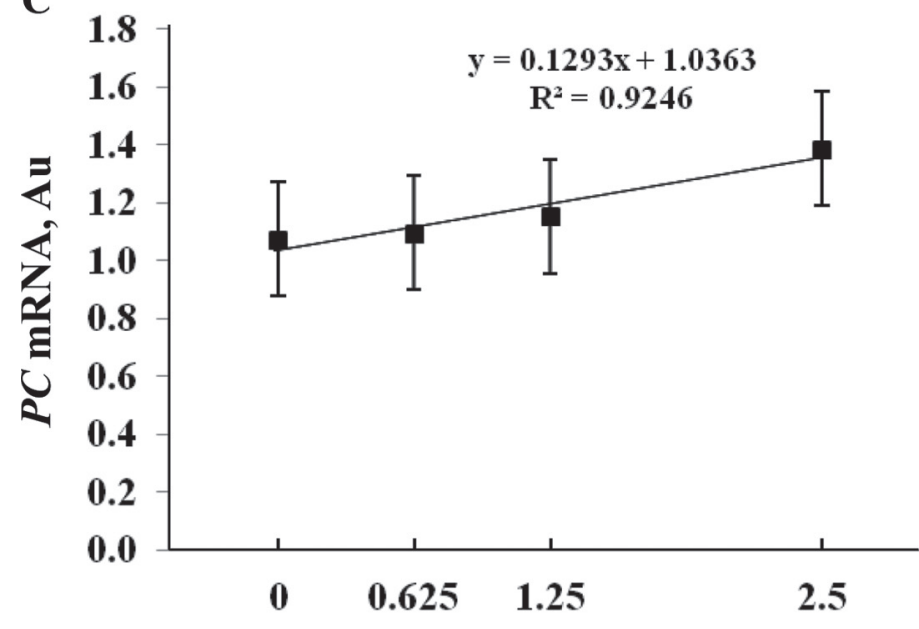

Propionate concentration, $\mathbf{m} M$ and insulin in regulating $P C K 1 \mathrm{mRNA}$ in any species. Whether the regulation of $P C K 1 \mathrm{mRNA}$ by propionate is transcriptionally controlled in bovine, as is the case for PCK1 in rat liver cells (Hanson and Patel, 1994; Hanson and Reshef, 1997), remains to be determined.

In contrast to $P C K 1$, expression of $P C K 2$ mRNA is generally considered constitutive and lacks acute hormonal and nutritional regulation (Beale et al., 2007). Our data confirmed the lack of regulation of PCK2 by hormones, including cAMP and dexamethasone; however, propionate induces $P C K 2$ mRNA expression in a concentration-dependent manner in bovine hepatocytes. The significant role of $P C K 2$ in gluconeogenesis, lipid metabolism, and trichloroacetic acid cycle activity

B

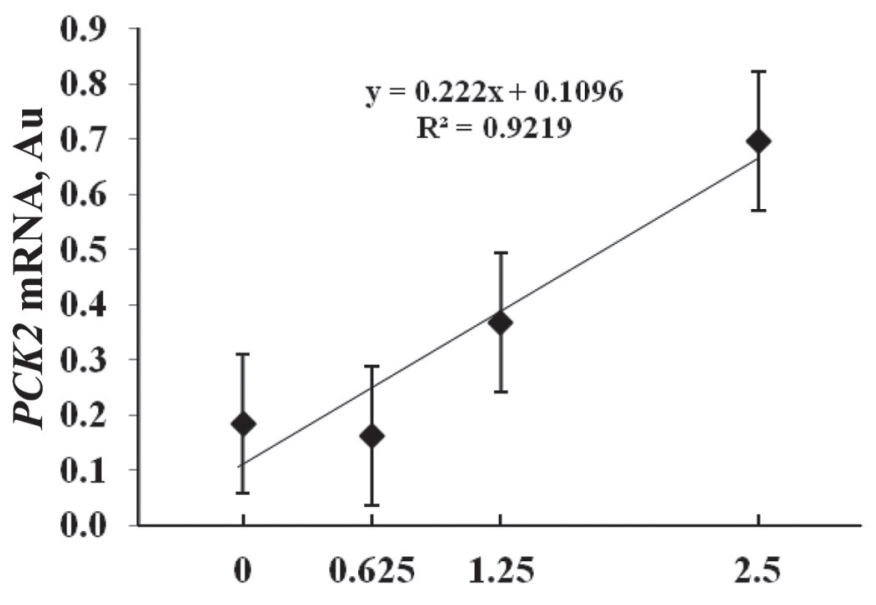

D

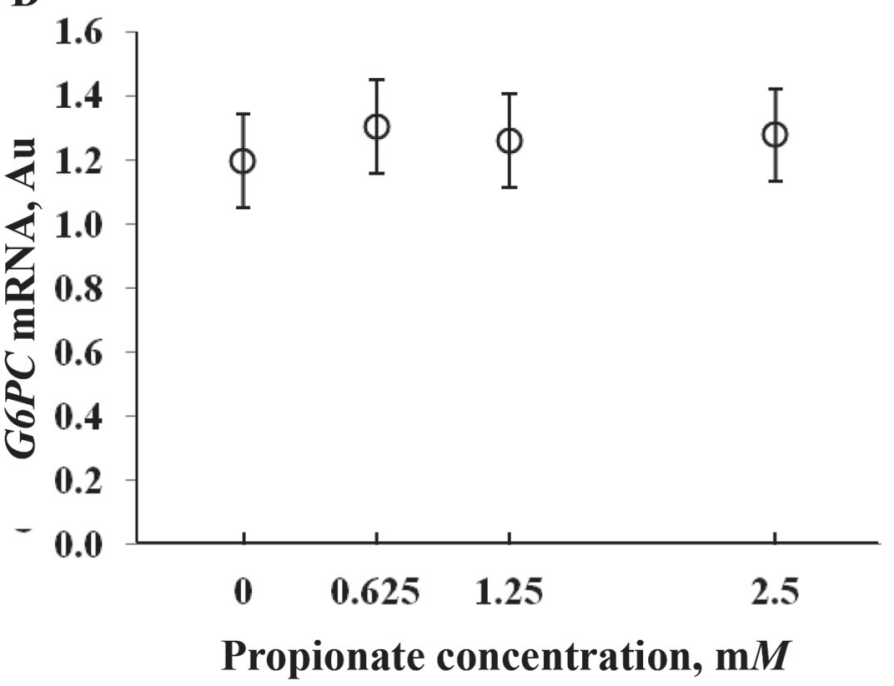

Figure 2. (A) Effects of propionate concentration on expression of cytosolic phosphoenolpyruvate carboxykinase $(P C K 1)$ mRNA, (B) mitochondrial phosphoenolpyruvate carboxykinase (PCK2) mRNA, $(\mathrm{C})$ pyruvate carboxylase $(P C)$ mRNA, and (D) glucose-6-phosphotase (G6PC) mRNA in bovine calf hepatocytes. After $24 \mathrm{~h}$, hepatocytes were exposed to 0, 0.625, 1.25, or $2.5 \mathrm{~m} M$ propionate for $6 \mathrm{~h}$ and then harvested for mRNA analysis. Data are expressed as arbitrary units of mRNA adjusted for $18 \mathrm{~S}$ abundance. Values are LSM $\pm \mathrm{SE}(\mathrm{n}=3$ cell preparations). Expression of $P C K 1$ and $P C K 2$ shows a linear effect $(P \leq 0.05)$ with increasing propionate concentrations. 

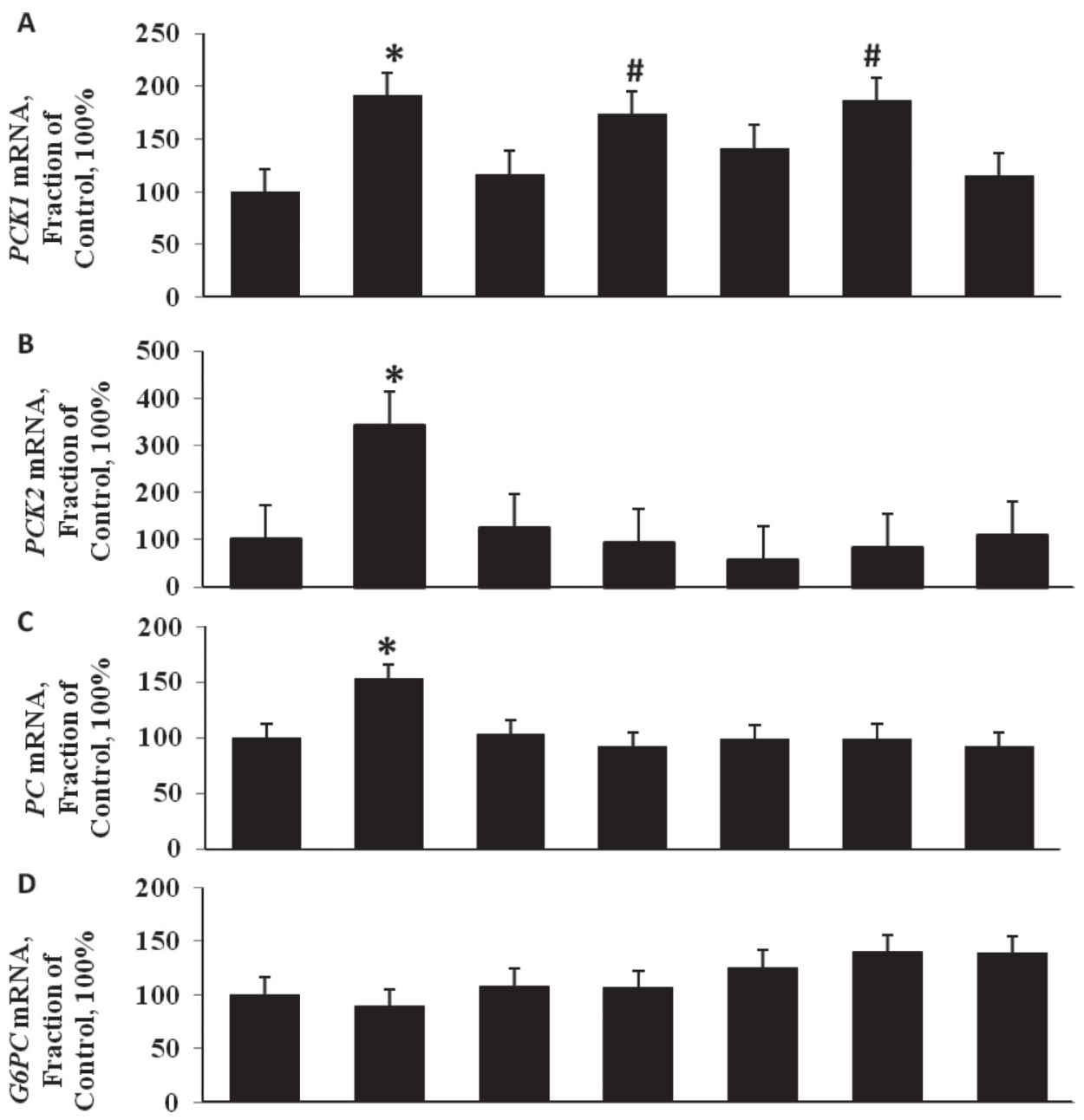

200
150
10
5

\section{Propionate $(2.5 \mathrm{mM})$ \\ cAMP (1.0 mM)}

Dexamethasone $(5.0 \mu M)$ Insulin $(100 \mathrm{nM})$

Figure 3. Effects of propionate, insulin, cyclic AMP (cAMP), dexamethasone, and combinations on mRNA expression of (A) cytosolic phosphoenolpyruvate carboxykinase $(P C K 1),(\mathrm{B})$ mitochondrial phosphoenolpyruvate carboxykinase $(P C K 2),(\mathrm{C})$ pyruvate carboxylase $(P C)$, and (D) glucose-6-phosphotase $(G 6 P C)$ in bovine calf hepatocytes. After $24 \mathrm{~h}$, hepatocytes were exposed to treatments for $6 \mathrm{~h}$ and then harvested for mRNA analysis. Data are expressed as fold induction of $P C K 1 \mathrm{mRNA}$ for each treatment relative to the no-addition control. Values are LSM $\pm \mathrm{SE}\left(\mathrm{n}=3\right.$ cell preparations). Means with the symbol $\left.*^{*}\right)$ differ $(P \leq 0.05)$ from the no-addition control, and means with the symbol (\#) tend to differ $(0.05<P \leq 0.10)$ from the no-addition control.

has been recently emphasized by overexpression models of $P C K 2$, in PCK1 knockout mice and in hepatocytes (Méndez-Lucas et al., 2013), and gene silencing models of PCK2 (Stark et al., 2014). In contrast to the rat and mouse liver, in which PCK2 only accounts for about 5 and $1 \%$ of the total phosphoenolpyruvate carboxykinase activity, respectively (Nordlie and Lardy, 1963; Wiese et al., 1991), ruminants present approximately equal activities of PCK1 and PCK2 (Agca et al., 2002). Approximately $60 \%$ of propionate flux to glucose depends on the enzyme $P C K 2$ in goat hepatocytes (Aiello and Armentano, 1987). The inductive effect of propionate on $P C K 2$ gene expression and counteractive effect of insulin on propionate-stimulated $P C K 2$ gene expression has brought new insights regarding the nutritional and hormonal regulation of $P C K 2$ expression. However, limited available supporting data makes it difficult to predict whether the changes in PCK2 mRNA would result in changes of in the enzyme expression and activity and relevant physiological consequences. 
Pyruvate carboxylase catalyzes the formation OAA from pyruvate and is an important intermediate for both gluconeogenesis and fatty acid oxidation (Jitrapakdee et al., 2008). The expression of $P C$ mRNA is increased during feed restriction (Velez and Donkin, 2005) and at parturition in transition dairy cows (Greenfield et al., 2000), and serves to support increased gluconeogenesis from lactate and gluconeogenic AA for lactation (Aschenbach et al., 2010). Our data demonstrate that increased propionate can also induce $P C$ mRNA expression, even though gluconeogenesis from propionate does not directly rely on $P C$. Our results are in accordance with a previous report that shows linear induction of $P C$ mRNA expression by propionate in neonatal bovine hepatocytes (Xu and Wang, 2006). An increase in $P C$ mRNA expression directly reflects an increased enzyme activity in dairy cattle (Greenfield et al., 2000). Because OAA pool size is determined by the activities of $P C K$ and $P C$, a matched increase in both enzymes may be important for maintaining the OAA pool and preventing the drainage of OAA from the trichloroacetic acid cycle. Reduction of OAA pool has been considered as a major cause of ketosis in dairy cows (Baird et al., 1968). The propionate-induced PC mRNA expression is not mimicked by the hormonal cues in the present study, which is consistent with previous reports that the transcriptional activities of bovine $P C$ promoters are not regulated by hormones such as dexamethasone (White et al., 2011). The regulation of $P C$ expression by fatty acids through activation of bovine $P C$ promoter 1 indicates nutritional control of bovine $P C$ gene transcription (White et al., 2011), which also appears to be the case for propionate. The inhibition of insulin on propionate-stimulated $P C$ mRNA expression is consistent with previous studies in which gluconeogenesis from propionate is decreased by insulin in isolated bovine primary hepatocytes (Donkin and Armentano, 1994, 1995). Insulin was reported to inhibit rat $P C$ gene transcription through its proximal promoter (Jitrapakdee et al., 1997). Nevertheless, the underlying molecular mechanism by which propionate and insulin regulate $P C$ mRNA expression in bovine remains to be elucidated.

Expression of $G 6 P C$ mRNA is not regulated by propionate in the present study, despite the increases in other key gluconeogenic genes. The metabolism of glucose-6-phosphate ( $\mathbf{G 6 P}$ ) by $G 6 P C$ is necessary to release glucose from the hepatocyte. Intracellular G6P may also be metabolized to glycogen by glycogen kinase. Propionate has been shown to stimulate glycogen synthesis in hepatocytes isolated from fed sheep in a concentration-dependent manner, and the induction is mediated through increased intracellular concentration of metabolic intermediaries, including OAA, phospho- enolpyruvate, and G6P (Morand et al., 1990). Lack of stimulation of $G 6 P C$ mRNA to match changes in $P C K 1, P C K 2$, and $P C$ mRNA may indicate either increased glycogen storage or adequate reserve capacity of $G 6 P C$ to accommodate additional G6P, potentially resulting from increased $P C K 1, P C K 2$, and $P C$ mRNA in response to propionate, or a combination of both processes.

Glucose production from propionate and lactate in neonatal calf hepatocytes have been shown to be regulated by substrates concentrations (Donkin and Armentano, 1994). However, the rate of gluconeogenesis from lactate is lower relative to propionate (Donkin and Armentano, 1994) and attributed to unknown factor(s) that limit conversion of lactate, but not propionate to glucose (Armentano, 1992; Donkin and Armentano, 1994). The present study demonstrates that propionate can directly induce expression of mRNA expression of PCK1, PCK2, and $P C$ in bovine hepatocytes, which may be the underlying mechanism for the stimulation of glucose production from propionate.

\section{CONCLUSIONS}

Overall, these data indicate a role of propionate to regulate its own metabolism through induction of PCK1, PCK2, and PC mRNA expression in isolated bovine hepatocytes. The effect of propionate on PCK1 mRNA expression is mimicked by cAMP. Propionate and cAMP induction of $P C K 1$ mRNA expression is eliminated by the addition of insulin. These data provide evidence of a direct action of propionate to control expression of mRNA for key enzymes for gluconeogenesis in ruminants.

\section{ACKNOWLEDGMENTS}

This project was supported in part by National Research Initiative Competitive Grant no. 2006-3520616646 from the USDA National Institute of Food and Agriculture (Washington, DC).

\section{REFERENCES}

Agca, C., R. B. Greenfield, J. R. Hartwell, and S. S. Donkin. 2002. Cloning and characterization of bovine cytosolic and mitochondrial PEPCK during transition to lactation. Physiol. Genomics 11:53-63.

Aiello, R. J., and L. E. Armentano. 1987. Gluconeogenesis in goat hepatocytes is affected by calcium, ammonia and other key metabolites but not primarily through cytosolic redox state. Comp. Biochem. Physiol. B 88:193-201.

Armentano, L. E. 1992. Ruminant hepatic metabolism of volatile fatty acids, lactate and pyruvate. J. Nutr. 122(Suppl):838-842.

Aschenbach, J. R., N. B. Kristensen, S. S. Donkin, H. M. Hammon, and G. B. Penner. 2010. Gluconeogenesis in dairy cows: the secret of making sweet milk from sour dough. IUBMB Life 62:869-877. 
Baird, G. D., K. G. Hibbitt, and G. D. Hunter. 1968. Biochemical aspects of bovine ketosis. Biochem. J. 107:683-689.

Beale, E. G., B. J. Harvey, and C. Forest. 2007. PCK1 and PCK2 as candidate diabetes and obesity genes. Cell Biochem. Biophys. 48:89-95.

Bobe, G., J. C. Velez, D. C. Beitz, and S. S. Donkin. 2009. Glucagon increases hepatic mRNA concentrations of ureagenic and gluconeogenic enzymes in early-lactation dairy cows. J. Dairy Sci. 92:5092-5099.

Christ, B., A. Nath, H. Bastian, and K. Jungermann. 1988. Regulation of the expression of the phosphoenolpyruvate carboxykinase gene in cultured rat hepatocytes by glucagon and insulin. Eur. J. Biochem. 178:373-379.

Dohoo, I. R., and S. W. Martin. 1984. Subclinical ketosis: Prevalence and associations with production and disease. Can. J. Comp. Med. $48: 1-5$.

Donkin, S. S., and L. E. Armentano. 1993. Preparation of extended in vitro cultures of bovine hepatocytes that are hormonally responsive. J. Anim. Sci. 71:2218-2227.

Donkin, S. S., and L. E. Armentano. 1994. Regulation of gluconeogenesis by insulin and glucagon in the neonatal bovine. Am. J. Physiol. 266:R1229-R1237.

Donkin, S. S., and L. E. Armentano. 1995. Insulin and glucagon regulation of gluconeogenesis in preruminating and ruminating bovine. J. Anim. Sci. 73:546-551.

Duffield, T. F., D. Sandals, K. E. Leslie, K. Lissemore, B. W. McBride, J. H. Lumsden, P. Dick, and R. Bagg. 1998. Efficacy of monensin for the prevention of subclinical ketosis in lactating dairy cows. J. Dairy Sci. 81:2866-2873.

Filsell, O. H., I. G. Jarrett, P. H. Taylor, and D. B. Keech. 1969. Effects of fasting, diabetes and glucocorticoids on gluconeogenic enzymes in the sheep. Biochim. Biophys. Acta 184:54-63.

Granner, D., T. Andreone, K. Sasaki, and E. Beale. 1983. Inhibition of transcription of the phosphoenolpyruvate carboxykinase gene by insulin. Nature 305:549-551.

Granner, D. K., K. Sasaki, and D. Chu. 1986. Multihormonal regulation of phosphoenolpyruvate carboxykinase gene transcription. Ann. N. Y. Acad. Sci. 478:175-190.

Greenfield, R. B., M. J. Cecava, and S. S. Donkin. 2000. Changes in mRNA expression for gluconeogenic enzymes in liver of dairy cattle during the transition to lactation. J. Dairy Sci. 83:1228-1236.

Hanson, R. W., and Y. M. Patel. 1994. Phosphoenolpyruvate carboxykinase (GTP): The gene and the enzyme. Adv. Enzymol. Relat. Areas Mol. Biol. 69:203-281.

Hanson, R. W., and L. Reshef. 1997. Regulation of phosphoenolpyruvate carboxykinase (GTP) gene expression. Annu. Rev. Biochem. 66:581-611.

Huntington, G. B. 1990. Energy metabolism in the digestive tract and liver of cattle: Influence of physiological state and nutrition. Reprod. Nutr. Dev. 30:35-47.

Jitrapakdee, S., G. W. Booker, A. I. Cassady, and J. C. Wallace. 1997. The rat pyruvate carboxylase gene structure. Alternate promoters generate multiple transcripts with the $5^{\prime}$-end heterogeneity. J. Biol. Chem. 272:20522-20530.

Jitrapakdee, S., M. St Maurice, I. Rayment, W. Cleland, J. Wallace, and P. Attwood. 2008. Structure, mechanism and regulation of pyruvate carboxylase. Biochem. J. 413:369-387.

Karcher, E. L., M. M. Pickett, G. A. Varga, and S. S. Donkin. 2007. Effect of dietary carbohydrate and monensin on expression of glu- coneogenic enzymes in liver of transition dairy cows. J. Anim. Sci. 85:690-699.

Massillon, D., I. J. Arinze, C. Xu, and F. Bone. 2003. Regulation of glucose-6-phosphatase gene expression in cultured hepatocytes and H4IIE cells by short-chain fatty acids: Role of hepatic nuclear factor-4a. J. Biol. Chem. 278:40694-40701.

Méndez-Lucas, A., J. A. G. Duarte, N. E. Sunny, S. Satapati, T. He, X. Fu, J. Bermúdez, S. C. Burgess, and J. C. Perales. 2013. PEPCK$\mathrm{M}$ expression in mouse liver potentiates, not replaces, PEPCK-C mediated gluconeogenesis. J. Hepatol. 59:105-113.

Morand, C., C. Redon, C. Remesy, and C. Demigne. 1990. Non-hormonal and hormonal control of glycogen metabolism in isolated sheep liver cells. Int. J. Biochem. 22:873-881.

Nordlie, R. C., and H. A. Lardy. 1963. Mammalian liver phosphoenolpyruvate carboxykinase activities. J. Biol. Chem. 238:2259-2263.

O'Brien, R. M., and D. K. Granner. 1990. PEPCK gene as model of inhibitory effects of insulin on gene transcription. Diabetes Care 13:327-339.

Salavert, A., and P. B. Iynedjian. 1982. Regulation of phosphoenolpyruvate carboxykinase (GTP) synthesis in rat liver cells. Rapid induction of specific mRNA by glucagon or cyclic AMP and permissive effect of dexamethasone. J. Biol. Chem. 257:13404-13412.

Sasaki, K., T. P. Cripe, S. R. Koch, T. L. Andreone, D. D. Petersen, E. G. Beale, and D. K. Granner. 1984. Multihormonal regulation of phosphoenolpyruvate carboxykinase gene transcription. The dominant role of insulin. J. Biol. Chem. 259:15242-15251.

Sauer, F. D., J. K. G. Kramer, and W. J. Cantwell. 1989. Antiketogenic effects of monensin in early lactation. J. Dairy Sci. 72:436-442.

Smith, R. W., R. A. Knight, and A. Walsh. 1982. Activities of some enzymes of glucose metabolism in bovine liver and kidney cortex at three stages of lactation. Res. Vet. Sci. 33:287-289.

Stark, R., F. Guebre-Egziabher, X. Zhao, C. Feriod, J. Dong, T. C. Alves, S. Ioja, R. L. Pongratz, S. Bhanot, and M. Roden. 2014 A role for mitochondrial phosphoenolpyruvate carboxykinase (PEPCK-M) in the regulation of hepatic gluconeogenesis. J. Biol. Chem. 289:7257-7263.

Taylor, P. H., J. C. Wallace, and D. B. Keech. 1971. Gluconeogenic enzymes in sheep liver: Intracellular localization of pyruvate carboxylase and phosphoenolpyruvate carboxykinase in normal, fasted and diabetic sheep. Biochim. Biophys. Acta 237:179-191.

Velez, J. C., and S. S. Donkin. 2005. Feed restriction induces pyruvate carboxylase but not phosphoenolpyruvate carboxykinase in dairy cows. J. Dairy Sci. 88:2938-2948.

White, H. M., S. L. Koser, and S. S. Donkin. 2011. Differential regulation of bovine pyruvate carboxylase promoters by fatty acids and peroxisome proliferator-activated receptor- $\alpha$ agonist. J. Dairy Sci. 94:3428-3436.

Wiese, T. J., D. O. Lambeth, and P. D. Ray. 1991. The intracellular distribution and activities of phosphoenolpyruvate carboxykinase isozymes in various tissues of several mammals and birds. Comp. Biochem. Physiol. B 100:297-302.

$\mathrm{Xu}, \mathrm{C}$., and Z. Wang. 2006. Effect of propionate, pyruvate and $\beta$-hydroxybutyric acid on pyruvate carboxylase mRNA expression of in vitro culture bovine hepatocytes. Anim. Sci. J. 77:440-446.

Zhang, Q., S. L. Koser, B. J. Bequette, and S.S. Donkin. 2015. Effect of propionate on mRNA expression of key genes for gluconeogenesis in liver of dairy cattle. J. Dairy Sci. 98:8698-8709. 